\title{
A AVALIAÇÃO DO PROGRAMA BRASILEIRO DE ETIQUETAGEM VEICULAR DEMONSTRA A NECESSIDADE DA MELHORIA CONTÍNUA
}

Marcelo Pereira Bales ${ }^{1}$, Silmara Regina da Silva ${ }^{1}$, Cristiane Dias ${ }^{1}$ e Willian de Oliveira Santos ${ }^{2}$

\author{
${ }^{1}$ CETESB (Companhia Ambiental do Estado de São Paulo) \\ ${ }^{2}$ Universidade Nove de Julho \\ E-mails: cdias@sp.gov.br, mbales@sp.gov.br, silmsilva@sp.gov.br, \\ willian viper@hotmail.com
}

\section{RESUMO}

O Programa Brasileiro de Etiquetagem Veicular - PBEV - tem como objetivos disponibilizar ao consumidor a informação sobre o consumo de combustível como parâmetro adicional no processo de escolha e induzir à melhoria da eficiência energética da frota circulante, de forma a reduzir a demanda crescente por combustível no país. Implementado de forma voluntária a partir de 2009, vêm obtendo escala ano a ano com a incorporação de novos modelos. Os resultados dos indicadores de eficiência energética são positivos, com ganhos na maior parte das categorias de veículo mesmo sem a contrapartida de qualquer benefício fiscal ou financeiro para o fabricante ou consumidor. A partir de 2015 começa a ser impactado pelo Inovar Auto, programa de incentivo à indústria automobilística que inclui benefício fiscal, não apenas pela indução à adesão de quase a totalidade das marcas comercializadas no país ao PBEV, mas também com a introdução de novas tecnologias viabilizadas pelo incentivo fiscal. Os resultados das análises demonstram que existe a necessidade da manutenção de um regime de atualização permanente na classificação dos veículos, de forma a evitar a maior concentração de modelos nas classes $A$ e $B$, que pode inviabilizar o processo de escolha do modelo mais econômico, fenômeno por qual passaram programas de eficiência energética de outros tipos de produtos.

\section{INTRODUÇÃO}

Em 2005, o Instituto Nacional de Metrologia, Normalização e Qualidade Industrial INMETRO, induzido por decisão do Comitê Gestor de Indicadores e Níveis de Eficiência Energética - CGIEE, deu início a estudo para desenvolver um programa com objetivo de medir o desempenho energético dos veículos comercializados no país. O Programa Brasileiro de Etiquetagem Veicular - PBEV, foi lançado no final de 2008. Desde 2009 o programa apresenta informações relacionadas à eficiência energética dos veículos comercializados no Brasil, buscando orientar e influenciar na decisão de compra do consumidor, que dessa forma pode levar em consideração o consumo de combustível, além do preço e outros atributos. 
Essas informações estão presentes em uma etiqueta aplicada nos veículos novos que informa a eficiência energética, comparando o modelo com outros da mesma categoria e a autonomia (km/l) conforme o tipo de combustível e o modo de uso, cidade e estrada. O PBEV desenvolveu metodologia inédita que considera a quantidade de energia presente nos diversos tipos de combustíveis adotados no país (gasolina, etanol e gás natural) e adota procedimentos de ensaios similares aos adotados para a determinação da emissão de poluentes atmosféricos dos veículos [1]. A Figura 1 apresenta um modelo de etiqueta aplicada nos veículos participantes do PBEV.

Figura 1 - Modelo de etiqueta do PBEV

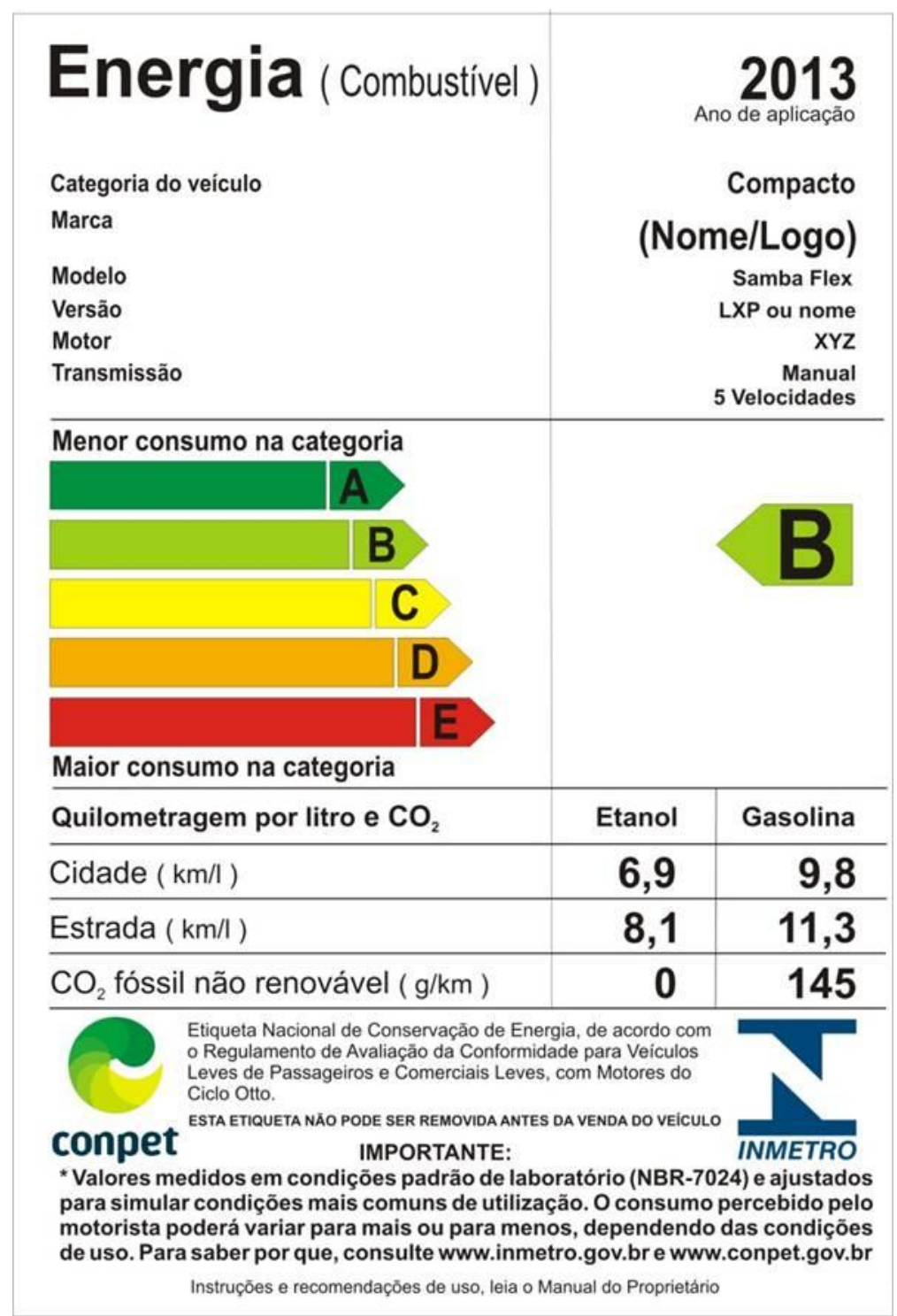

Fonte: Jornal Extra [2]

Diversas organizações participam da gestão do programa, entre elas o Programa Nacional da Racionalização do uso dos Derivados de Petróleo e do Gás Natural (CONPET), o Ministério do Desenvolvimento, Indústria e Comércio Exterior (MDIC), 
o Ministério de Minas e Energia (MME), a Agência Nacional do Petróleo, Gás Natural e Biocombustíveis (ANP), o Instituto Brasileiro do Meio Ambiente e dos Recursos Naturais Renováveis (IBAMA), a Companhia Ambiental do Estado de São Paulo (CETESB), o Centro de Pesquisas e Desenvolvimento da Petrobras (CENPES), a Associação Nacional dos Fabricantes de Veículos Automotores (ANFAVEA) e a Associação Brasileira de Empresas Importadoras e Fabricantes de Veículos Automotivos (ABEIFA).

O Programa Inovar Auto, criado pela Lei Federal 12.715/2012 (BRASIL, 2012), tem como um dos objetivos a melhoria da eficiência energética dos veículos comercializados no Brasil. Para alcançar tal objetivo, estabeleceu três metas progressivas para serem buscadas pelos fabricantes. Essas metas consistem de diferentes níveis de consumo de combustível por distância percorrida em função da massa dos veículos comercializados. $\mathrm{O}$ atendimento da primeira meta é obrigatório e o de cada uma das metas subsequentes é opcional e dá direito a benefícios fiscais também progressivos. A Figura 2 mostra as metas de eficiência energética do Inovar Auto em forma de gráfico. A linha superior em azul escuro é a linha base de 2012. A segunda linha, na cor verde, a meta obrigatória e as linhas inferiores, lilás e azul clara, as metas opcionais.

Figura 2 - Metas do Inovar Auto

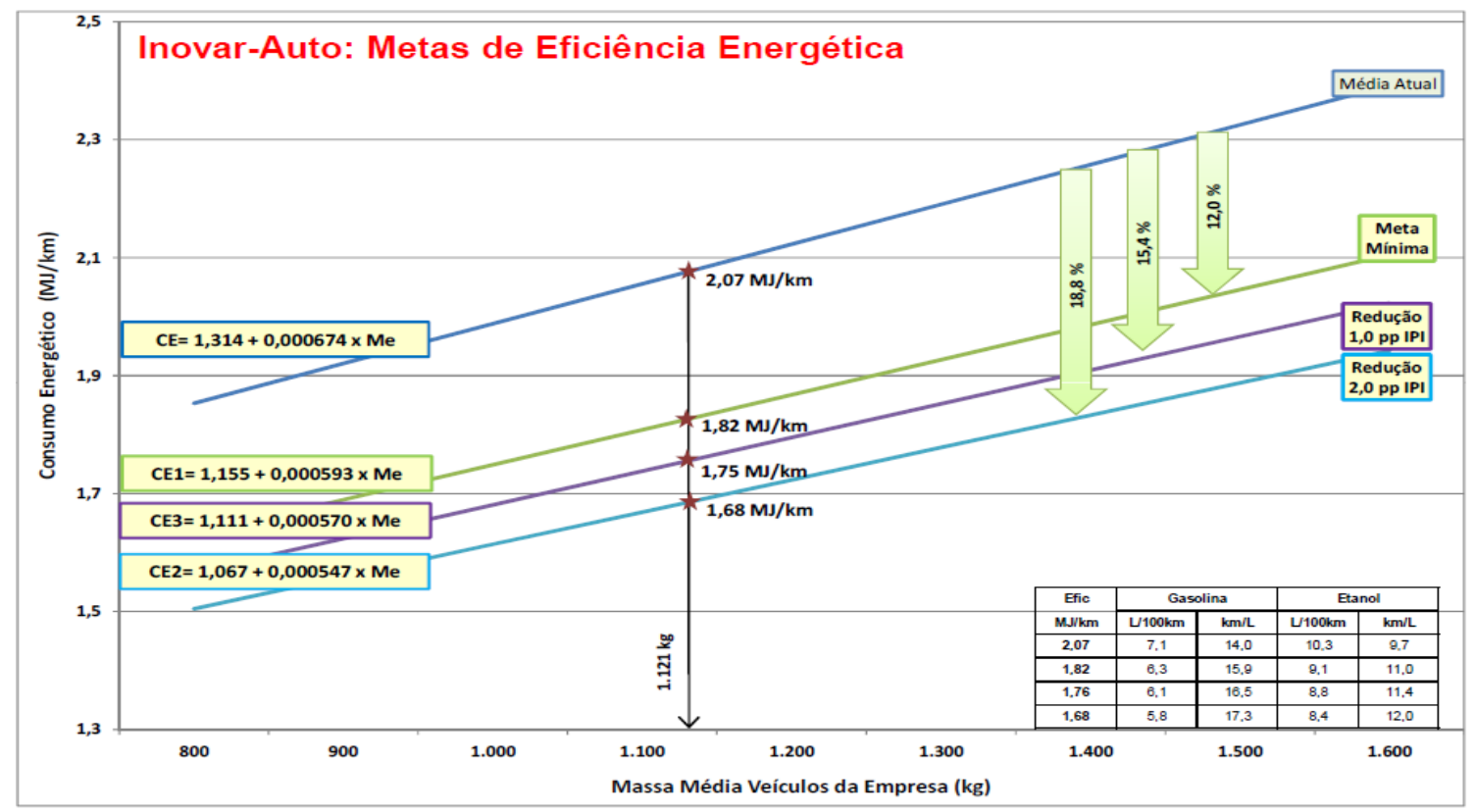

Fonte: JOSEPH JR (2014).

A participação dos fabricantes de automóveis no PBEV é voluntária e estabelecida anualmente. Sendo assim, um fabricante pode optar por participar ou não da avaliação do ano vigente. Entretanto, o Inovar Auto possibilitou que a participação no PBEV seja uma das opções para o atendimento a quesitos obrigatórios para habilitação. Nesse caso, a participação no PBEV passa a ser obrigatória durante a vigência do Inovar Auto. 
Para obter os valores do consumo de combustível dos veículos, o Inovar Auto adotou os mesmos procedimentos do PBEV para ensaios e para a conversão do consumo dos diversos combustíveis utilizados no Brasil em um padrão comparável, expresso em consumo de energia por distância percorrida na unidade: Mega-Joule por quilômetro $(\mathrm{MJ} / \mathrm{km})$.

Assim, tanto a evolução natural ou induzida da tecnologia dos veículos como a alteração significativa da participação dos fabricantes no PBEV em função do Inovar Auto, levam a necessidade de constante revisão de seus parâmetros e são fundamentais para o sucesso do programa.

\section{INFORMAÇÕES GERAIS}

A Tabela 1 faz apresenta um panorama geral da participação de modelos no programa no período de 2009-2014.

Tabela 1. Panorama Geral do Programa no Período 2009-2015

\begin{tabular}{|l|c|c|c|c|c|c|c|}
\hline Ano & 2009 & 2010 & 2011 & 2012 & 2013 & 2014 & 2015 \\
\hline Marcas & 5 & 6 & 6 & 8 & 37 & 36 & 36 \\
\hline Modelos & 31 & 67 & 68 & 103 & 285 & 352 & 369 \\
\hline Versões & 53 & 131 & 125 & 157 & 448 & 599 & 388 \\
\hline Nacionais & 50 & 55 & 49 & 79 & 123 & 164 & 156 \\
\hline Importados & 3 & 12 & 19 & 24 & 162 & 179 & 213 \\
\hline Flex & 49 & 53 & 53 & 91 & 148 & 190 & 179 \\
\hline Gasolina & 4 & 14 & 14 & 11 & 137 & 161 & 190 \\
\hline $\begin{array}{l}\text { Hibrido } \\
\text { Gasolina }\end{array}$ & - & - & 1 & 1 & 1 & 3 & 4 \\
\hline
\end{tabular}

Fonte: elaborado pelo autor.

Para a avaliação da eficiência energética, os veículos são separados por categorias, que refletem seu tamanho ou aplicação específica.

A classificação de cada modelo é feita comparando seu consumo com um valor de referência determinado pela portaria do INMETRO (BRASIL, 2011). Esse valor, obtido em 2011 pelo cálculo da mediana de consumo de combustível por categoria, permanece vigente até os dias de hoje.

As categorias que em 2011 não tinham pelo menos 10 modelos ou que foram criadas após esse ano tiveram o valor de referência determinado posteriormente. Algumas categorias ainda não tem um valor de referência.

As categorias com mediana fixada até 2015 são: Subcompacto, Compacto, Médio, Grande, Carga Derivado, Fora de Estrada, Utilitário Esportivo Compacto, Utilitário Esportivo Grande e Extra Grande. 
Conforme o consumo de combustível, os modelos são classificados por cores e letras. As etiquetas apresentam notas são atribuídas variando de "A" a "E" com as respectivas cores verde e vermelha.

\section{OBJETIVO}

O objetivo deste estudo é avaliar a evolução do consumo de combustível dos veículos participantes do PBEV, baseado na comparação entre os valores de referência atuais e as medianas estatísticas de consumo dos modelos declarados a cada ano, de forma a propor novos valores de referência para os próximos anos.

\section{RESULTADOS}

A Figura 1 apresenta os valores de referência, aqui chamados de medianas fixas e a medianas reais para a categoria Subcompacto. Observa-se que o valor de 2011 foi definido como o de referência para a categoria. Entretanto, a mediana do consumo dos modelos participantes ao longo dos anos foi decrescendo, atingindo $1,59 \mathrm{MJ} / \mathrm{km}$ no ano de 2015. A redução no período foi de aproximandamente $6 \%$.

Figura 1. Medianas reais e fixas da categoria Subcompacto no período de 2009 a 2015

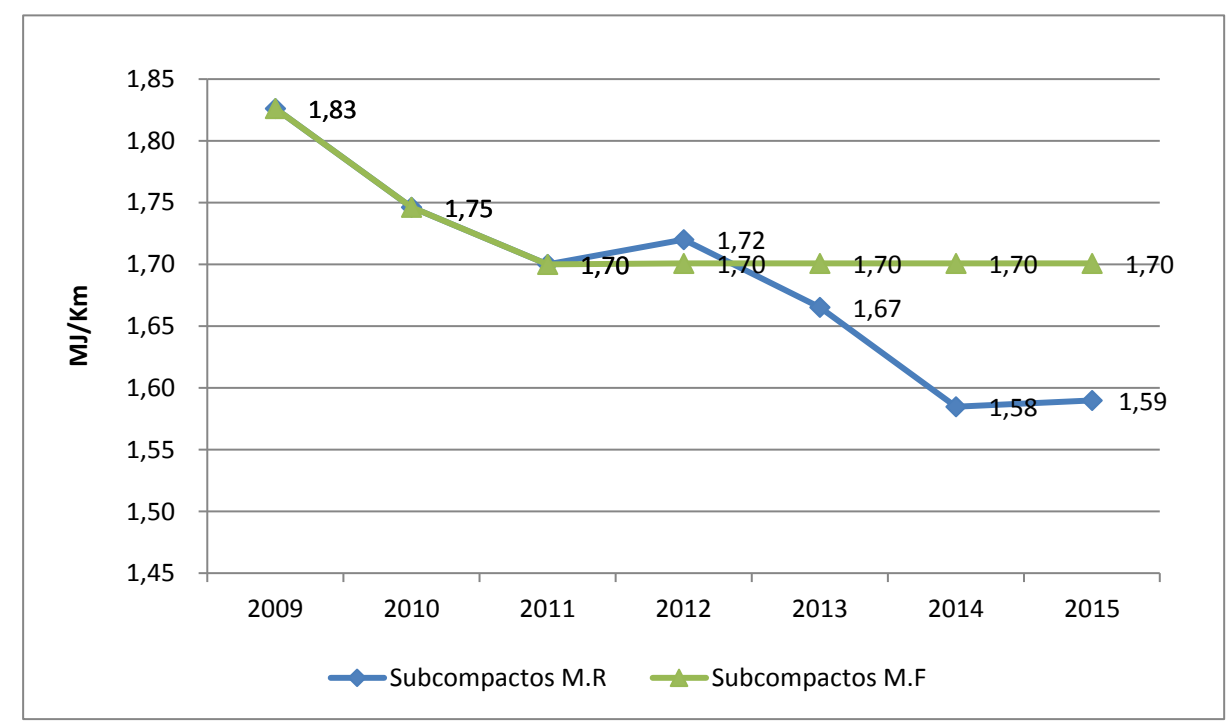

Fonte: elaborado pelo autor.

A Figura 2 apresenta as medianas fixas e reais para a categoria Compacto. Observa-se que a mediana do consumo dos modelos participantes ao longo dos anos foi decrescendo, atingindo $1,82 \mathrm{MJ} / \mathrm{km}$ no ano de 2015 . A redução no período foi de aproximandamente $3 \%$. 
Figura 2. Medianas reais e fixas da categoria Compacto no período de 2009 a 2015

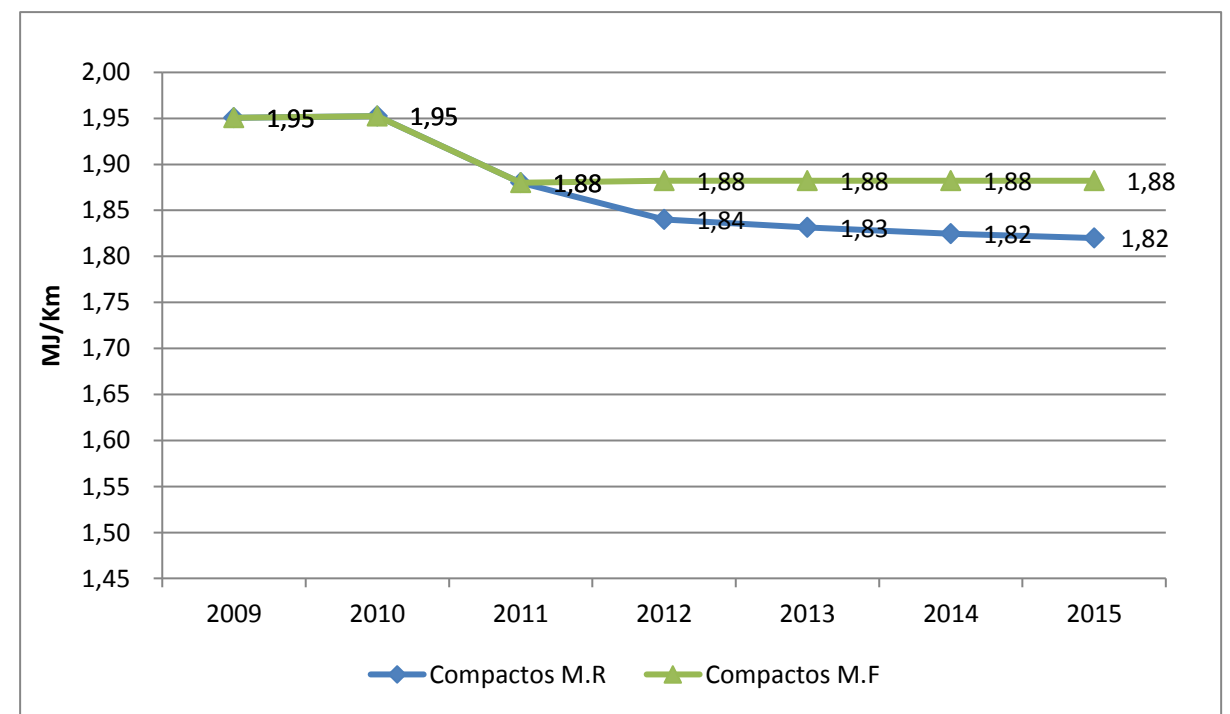

Fonte: elaborado pelo autor.

A Figura 3 apresenta as medianas fixas e reais para a categoria Médio. Observa-se que os valores de consumo de combustível eram menores que o de referência desde 2012. Em 2015, devido o acréscimo do numero de modelos, a mediana do consumo de combustível real aumentou. $O$ fato pode ser explicado pela introdução de modelos tecnologicamente defasados e que não estavam no PBEV por opção dos fabricantes.

Figura 3. Medianas reais e fixas da categoria Médio no período de 2009 a 2015

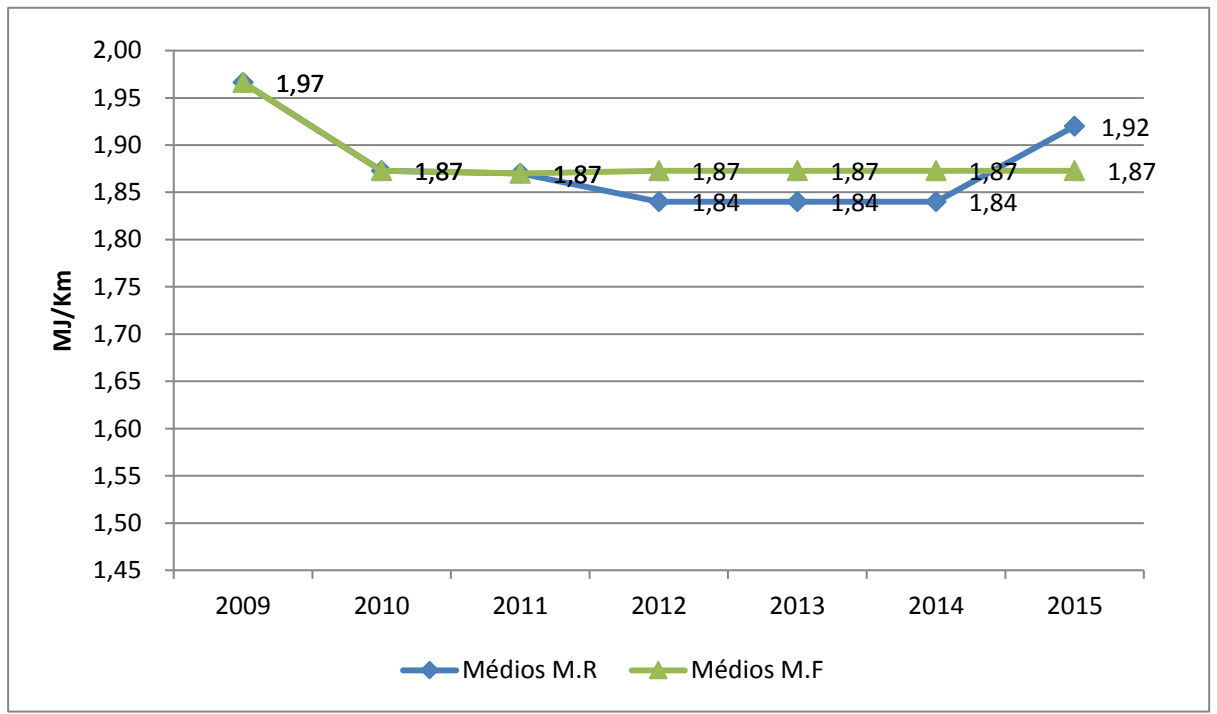

Fonte: elaborado pelo autor.

A Figura 4 apresenta as medianas fixas e reais para a categoria Grande. Observa-se que, com excessão do ano 2013, os valores de consumo de combustível mantêm-se muito próximo ao do valor de referência. 
Figura 4. Medianas reais e fixas da categoria Grande no período de 2009 a 2015

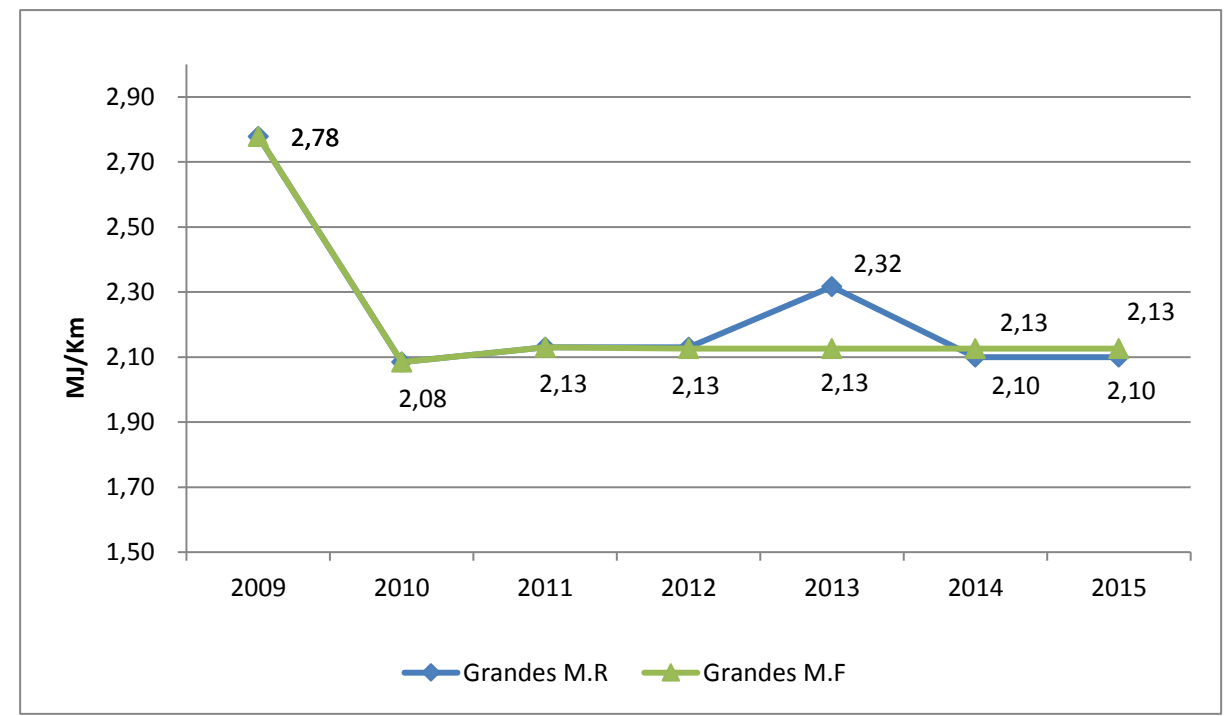

Fonte: elaborado pelo autor.

A Figura 5 apresenta as medianas fixas e reais para a categoria Carga Derivado. Observa-se que os valores das medianas de consumo de combustível estão menores, em média $5 \%$, que o valor de referência.

Figura 5. Medianas reais e fixas da categoria Carga Derivado no período de 2009 a 2015

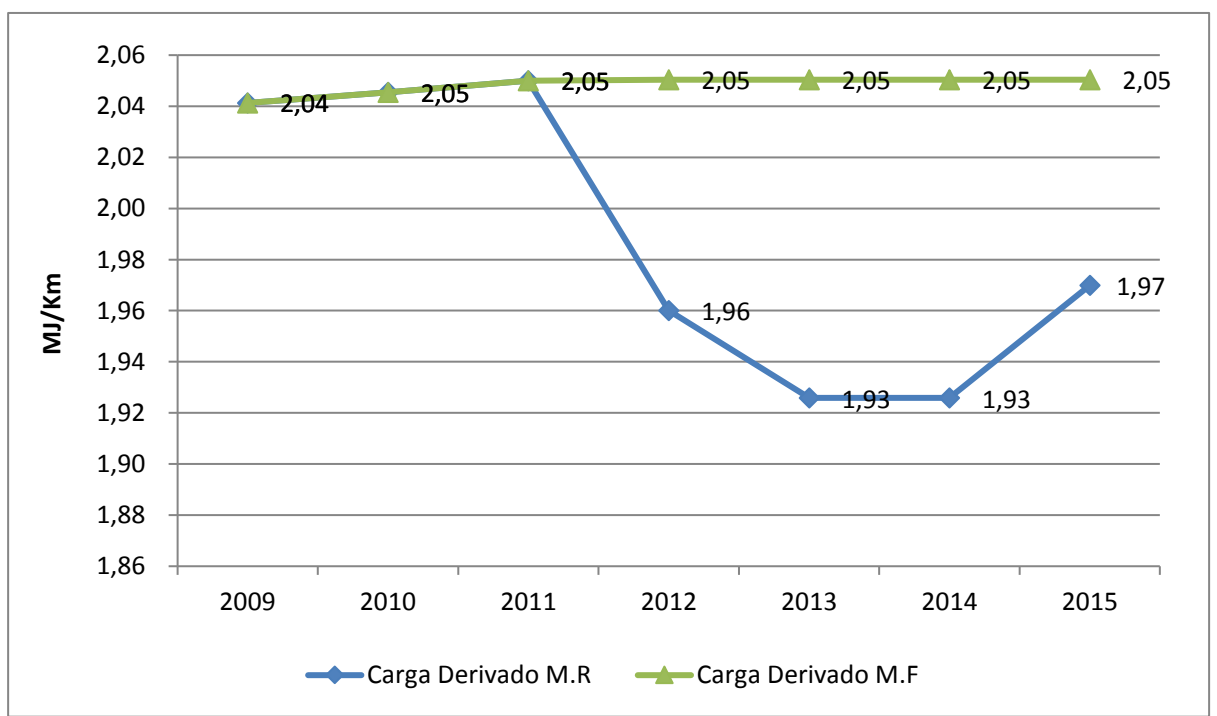

Fonte: elaborado pelo autor.

A Figura 6 apresenta as medianas fixas e reais para a categoria Fora de Estrada. Observa-se que, com excessão do ano 2014, os valores das medianas de consumo de combustível estão menores que o valor de referência. 
Figura 6. Medianas reais e fixas da categoria Fora de Estrada no período de 2009 a 2015

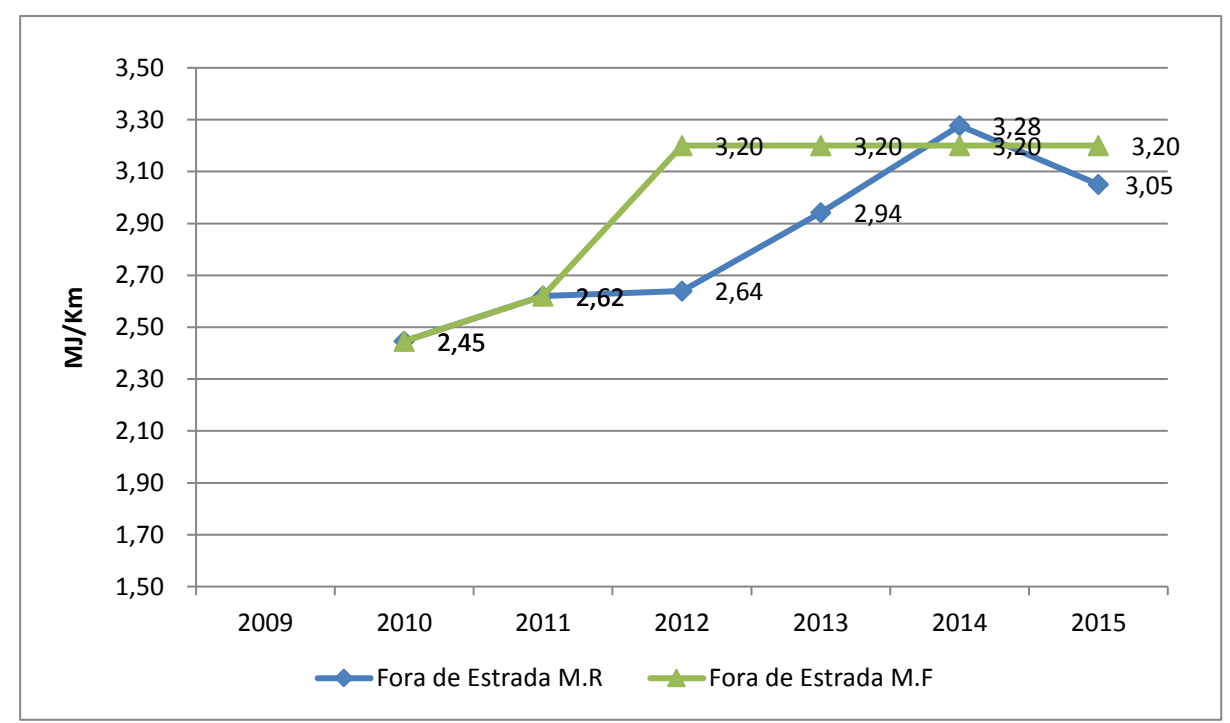

Fonte: elaborado pelo autor.

As figuras 7, 8 e 9 apresentam as medianas fixas e reais das categorias que foram introduzidas em 2014: Utilitário Esportivo Compacto, Utilitário Esportivo Grande e Extra Grande. Os valores de referência adotados foram baseados em dados em 2013.

Observa-se que nas categorias Utilitário Esportivo Compacto e Utilitário Esportivo Grande os valores de 2015 são menores que os de referência e no caso da categoria Extra Grande está 5\% maior que o valor de referência.

Figura 7. Medianas reais e fixas da categoria Utilitário Esportivo Compacto no período de 2014 e 2015

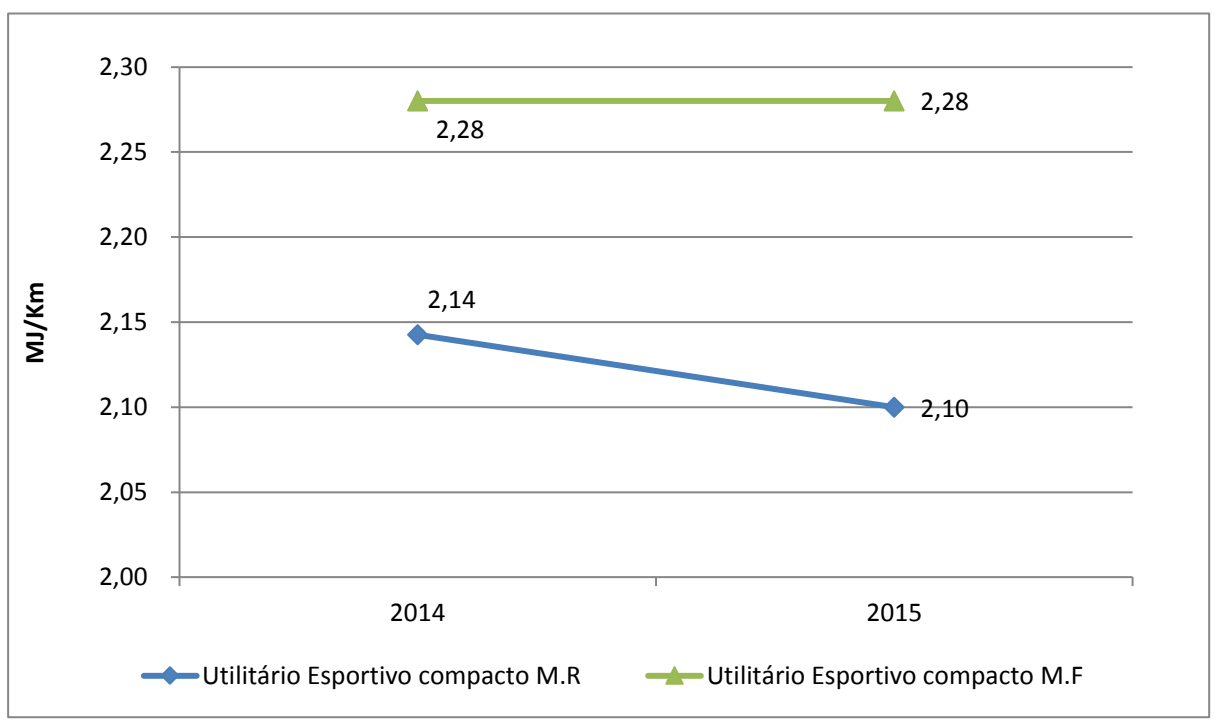

Fonte: elaborado pelo autor. 
Figura 8. Medianas reais e fixas da categoria Utilitário Esportivo Grande no período de 2014 e 2015

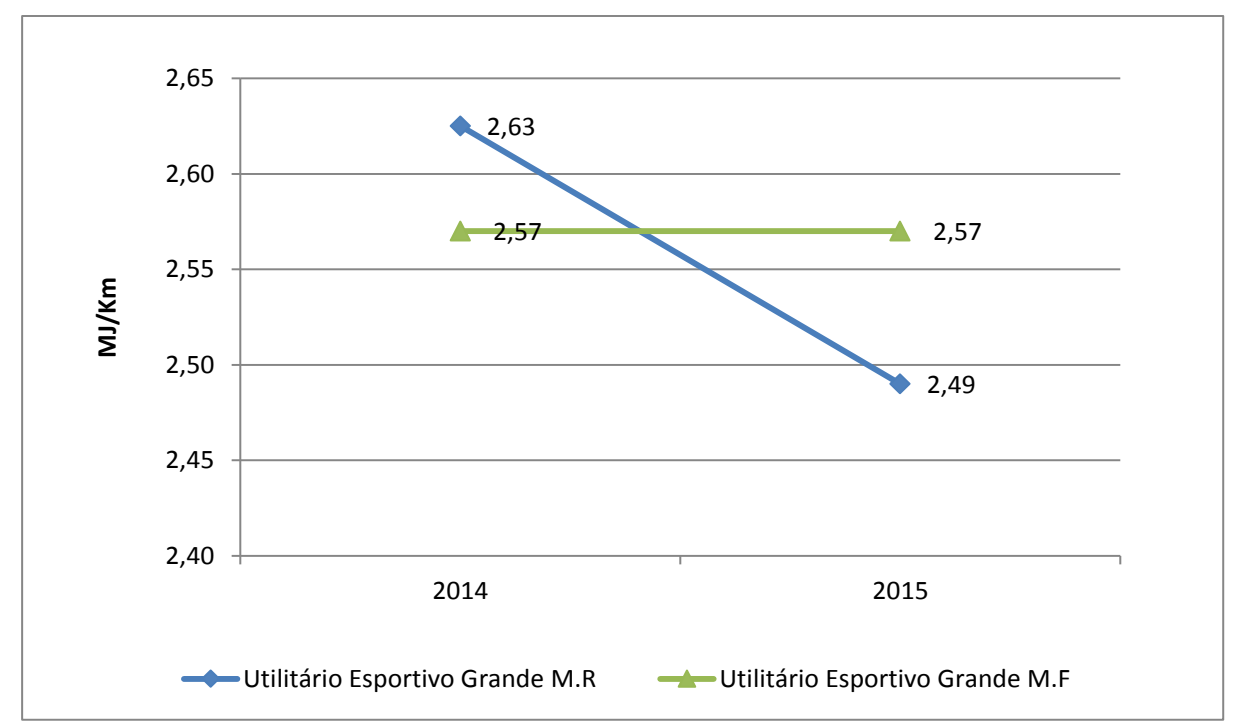

Fonte: elaborado pelo autor.

Figura 7. Medianas reais e fixas da categoria Extra Grande no período de 2014 e 2015

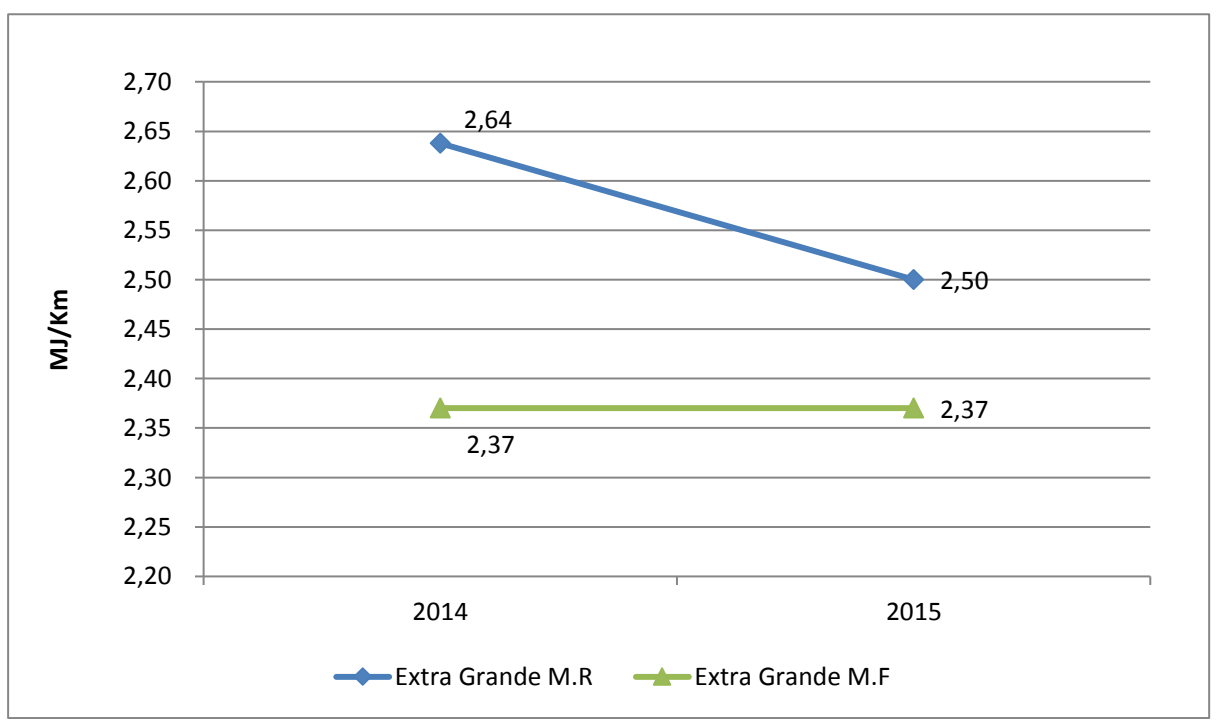

Fonte: elaborado pelo autor.

\section{ANÁLISE DOS RESULTADOS}

De forma geral, podemos constatar que os modelos participantes do PBEV, que representam quase a totalidade das marcas comercializadas no Brasil no ano de 2014, apresentam consumo de combustível menor que os valores de referência, quando utilizamos o conceito estatístico de mediana. 
A tendência, nesse caso, é o aumento do número de modelos classificados como $\mathrm{A}$ e $B$, ou seja, que possuem consumo de combustível menor que o valor de referência.

Algumas categorias apresentaram características diferentes, como as dos Médios e Grandes. Nesse caso, os valores de referência precisam ser mantidos. O PBEV tem estabelecido como regra que os valores de referência não podem aumentar, ou seja, o consumo de combustível de referência não pode ser pior.

Os valores das medianas de consumo de combustível no ano de 2015 podem ser tomados como valores de referência para o próximo período (2016 a 2018). Em 2018 os veículos comercializados no Brasil já estarão equipados com as tecnologias de melhoria da eficiência energética e terão a partir daí uma evolução natural, exceto se novo programa indutor for lançado no período, como por exemplo, uma segunda fase do Inovar Auto.

A Tabela 2 mostra os valores de consumo de combustível por categoria propostos a partir dos valores de 2015. No caso em que o valor de 2015 foi maior que o de referência mantêm-se o atual.

Tabela 2 - Valores de consumo de combustível propostos para o período de 2016 a 2018 para o PBEV baseado na evolução das medianas.

\begin{tabular}{|l|c|c|c|}
\hline \multicolumn{1}{|c|}{ Categoria } & $\begin{array}{c}\text { Valor de } \\
\text { Referência } \\
\text { atual }\end{array}$ & $\begin{array}{c}\text { Valor de } \\
\text { Referência } \\
\text { proposto }\end{array}$ & Variação (\%) \\
\hline Sub Compactos & 1,70 & 1,59 & $-7 \%$ \\
\hline Compactos & 1,88 & 1,82 & $-3 \%$ \\
\hline Médios & 1,87 & 1,87 & $0 \%$ \\
\hline Grandes & 2,13 & 2,10 & $-1 \%$ \\
\hline Carga Derivado & 2,05 & 1,97 & $-4 \%$ \\
\hline Fora de Estrada & 3,20 & 3,05 & $-5 \%$ \\
\hline Utilitário Esportivo compacto & 2,28 & 2,10 & $-8 \%$ \\
\hline Utilitário Esportivo Grande & 2,57 & 2,49 & $-3 \%$ \\
\hline Extra grande & 2,37 & 2,37 & $0 \%$ \\
\hline
\end{tabular}

Fonte: elaborado pelo autor.

\section{CONCLUSÃO}

Os avanços tecnológicos típicos da indústria automobilística tendem a buscar a melhoria da eficiência energética dos veículos, considerando que uma existe uma parcela significativa de usuários de veículos mais econômicos.

O PBEV induz, em algum grau, a escolha dos modelos de veículos mais eficientes e portanto, leva os fabricantes a buscarem participação no mercado baseado também nesse quesito. 
O Inovar Auto tem uma meta obrigatória e duas metas opcionais para redução global do consumo de combustível. Ao longo do período de 2015 a 2017, os veículos comercializados no Brasil devem sofrer melhorias tecnológicas para reduzir o consumo de combustível e atender essas metas.

Esses fenômenos levam a redução do consumo de combustível dos veículos e, consequentemente, a redução das medianas de consumo de combustível dos veículos participantes do PBEV e a melhoria de classificação dos mesmos.

Para evitar esse acúmulo nas melhores classificações, os valores de referência das categorias do PBEV devem evoluir, reduzindo os padrões de consumo de combustível esperados e induzindo a melhoria do consumo dos veículos.

Para o período de amadurecimento do Inovar Auto, até o ano de 2018, é necessária a atualização dos valores de referência, baseada na análise das tendências das medianas de consumo do PBEV ao longo do período de 2009 a 2015.

\section{REFERÊNCIAS}

BRASIL. Ministério do desenvolvimento, Indústria e Comércio Exterior, Instituto Nacional de Metrologia, Qualidade e Tecnologia - INMETRO. Portaria n.․ 377, de 29 de setembro de 2011. Disponível em:

<http://www.inmetro.gov.br/legislacao/rtac/pdf/RTAC001739.pdf.> Acesso em: 22 maio 2015.

JORNAL EXTRA. Disponível em: <http://extra.globo.com/noticias/carros-emotos/pbev-traz-mais-uma-leva-de-carros-economicos-beberroes-6683689.html>. Acesso em: 25 maio 2015

JOSEPH JR, H. Impacto da continuidade do PROCONVE sobre Inovar Auto. In: SEMINÁRIO DE EMISSÕES, 2014, São Paulo. Apresentação, PDF, 21 slides, 1298KB. Disponível em: < http://www.aea.org.br/downloads/2014/emissoes/ >. Acesso em: 20 out. 2014. Documento não editado de acesso restrito aos participantes do evento. 